\title{
Stories from the English riverbank: How riparian communities interpret, articulate and action water resource sustainability
}

\author{
Dr. Mary Gearey ${ }^{1}$
}

\begin{abstract}
To effectively communicate sustainable policies and strategies at a societal level we first need to understand how water users themselves comprehend the challenges that management practitioners face. Understanding the different lifeworld perspectives of citizens who live and work alongside their water resources allows policy makers and practitioners to target messages which accord with individual's own experiences. Nexus governance thinking recognizes the integral role of water in cementing sustainable economic development and societal continuity, yet fails to capture the granularity of individual perceptions and responses with regards to water resources management. Through empirical fieldwork with residents in three UK waterside communities, interrogating a range of management issues, the research has begun to build a picture of where water 'sits' within individual lifeworlds. Cataloguing these local knowledges, responses and actions provides data to determine what types and what temporality of changes to water resources people will accept in support of sustainability.These insights reveal modes of community resilience which correspond with the key sustainability messages around changing water conditions and demonstrate the myriad ways water users have interpreted and responded to these articulations.
\end{abstract}

Keywords: Nexus governance, water resources management, sustainability, community resilience

\section{Introduction}

He thought his happiness was complete when, as he meandered aimlessly along, suddenly he stood by the edge of a full-fed river. Never in his life had he seen a river before - this sleek, sinuous, full-bodied animal, chasing and chuckling, gripping things with a gurgle and leaving them with a laugh, to fling itself on fresh playmates that shook themselves free, and were caught and held again. All was a-shake and a-shiver - glints and gleams and sparkles, rustle and swirl, chatter and bubble. The Mole was bewitched, entranced, fascinated.... and when tired at last, he sat on the bank, while the river still chattered on to him, a babbling procession of the best stories in the world, sent from the heart of the earth to be told at last to the insatiable sea. riverbank'.

The Wind in the Willows, Kenneth Grahame, Chapter 1 ( $p 4)$ : 'the

The riverbank has a central place within the English imagination, with a particularly rural sensibility aligned with tinkling brooks lined with willow trees. It is a place of serenity, of summertime, of manners, of benign wildlife, picnics, poetry, gentle diversions and dappled sunshine. It is, however, entirely fictional. Frozen within the 
stylised romantic Edwardian period of the English idyll which does not exist, and perhaps never existed, the English riverbank is part mythology, part affirmation of a landscape of a collective desire. The above quote, from a popular but now antiquated children's book, is both a synthesis and the origins of the mythologised English riverbank, populated by anthropomorphised animals who live both closely with nature and yet at a remove. Riddled with class normativity throughout the story, the character of Mole, poorly sighted, with a tendency to seclusion, is the everyman protagonist, the educated ditherer who leads the child reader through a joint voyage of discovery and wonderment, starting at the very beginning of the story with his initiation into life on the riverbank. The river is a dynamic playfellow, bewitching, mischievous, full of life and yet remains part of a bigger, wider, wilder life than poor Mole can grasp. Mole knows that the riverbank is somehow always eluding him, that he has only partial knowledge of real events, of the fabric of riverbank life with its rich variety of characters and events, always slightly out of reach.

The riverbank is then embedded in the cultural psyche. Asked to imagine a riverbank, we all have an image that comes to mind. For some, it is this quintessentially rural vision of abundance. For others it may symbolise something more profound - a boundary, an obstacle, a hazard which prevents a route or a journey. In our increasingly urbanized lives it may represent economic decreptitude, or the site of more sinister turns of human existence. What we can say is that we can all picture a riverbank, and this says something quite fundamental about the role that rivers play in our lives, and also how we feel about the way rivers are embedded within our life stories and the landscapes that we live in.

Water environments, the rivers, streams, lakes, ground water, aquifers and ponds, that we rely on for our freshwater resources face a range of acute challenges in the coming years - both in developed and developing countries. These dynamic changing water conditions are produced by a complex range of drivers, including water resource competition due to population rises and urban clustering, different, sometimes conflicting, use of catchments by a variety of stakeholders, together with factors associated with climate change perturbations (IPCC 2012). These changes are multifarious, multi-scalar and multi-temporal, and create unknown future pathways which require a re-evaluation both of natural resource management techniques and a shift in the way we as a society use and value water (Dovers and Handmer 1992).

Governments need to plan on a national and international level to ameliorate the impacts of climate change. As part of this process they must also work in tandem with private companies who are involved in the water sector, whose long term ability to commercially thrive is intimately connected both with sustainable use and guardianship of the resource, but also with ensuring their activities are profit making. Together, both the government and the private sector must connect with water users to clearly deliver messages around sustainable futures and sustainable uses of water. There is then a twofold challenge: Firstly the scale of sustainability planning - a national issue in a globalised context. Secondly, the ability to enable that sustainability planning in the context of privatised service delivery expectations. The next two sections will discuss these related concerns in 
more detail.

\section{IWRM, AM and Nexus approaches in support of resource sustainability}

Integrated water resources management (IWRM) is argued to be the first step towards a recognition of the embedded nature of key infrastructures in the future sustainability of economies. An in-depth critical engagement with the concept is outside the remit of this paper. IWRM's conceptual scale as an holistic approach to water management which seeks to address the needs of economy, people and ecosystem services (Biswas 2008) can leave it vulnerable to claims of over-ambition (Jeffrey and Gearey 2006). IWRM's focus on reconciling national systems with catchment based planning has been criticised for excluding specific ecosystems and expertise (Butterworth et al 2010). Even single river catchments can be populated by starkly different governance institutions and local water knowledges (Gearey and Jeffrey 2010, Strang 2004). There has been much criticism of IWRM levelled at its grand ambition to provide a generic, universal toolbox to shape water delivery systems. This has lead to what Mukhtarov \& Gerlak (2014) have described as a stalemate or impasse for IWRM, centred around the dominance of certain epistemologies. For Mukhtarov and Gerlak, the dominance of certain disciplinary perspectives, such as engineering or hydrology, in the creation of IWRM policies has had a tendency to exclude certain social and environmental actors and groups whose knowledge and expertise sit outside of these dominant narratives. Mukhtarov and Gerlak argue that it is 'knowledge versatility' that will enrich the IWRM approach and overcome this tendency towards normativity. In particular, the isolation of water as the central ambit point in developed economies has been pinpointed by turns as hierarchical (Hirsch 2011), vague (Biswas) and something of a political red herring (Allan 2003). Theorists such as Biswas (2008) and Benson, Gain and Rouillard (2014) go on to argue that IWRM stops short of delivering real utility; that identifying water alone as the critical infrastructure in any developed economy fails to address the need to link other 'chronic' interdependent sectors such as energy and food security. Chronic in this sense means nothing less than a continuous, essential part of a functioning society. Water is critical; but is not the only constituent part.

Adaptive Management approaches (AM) sought to address the rigidity of IWRM's tightly defined framework. Here, a learning by doing', experiential approach recognised the need to adapt policy to individual place, institutions and river catchments. Whilst a movement forward from IWRM it was argued by ecologists such as Walker and colleagues (2003) and Brugnach et al (2008) that elasticity of boundaries and plurality of contexts rendered it vulnerable to saying everything and doing nothing. Particularly for sustainability theorists (Poerksen 1995), a key element in adaptive and transformative planning is an ability to clearly signpost actions which will enable wholesale shifts in how we prepare for the impacts of climate change.

In recognition of the interdependence of national economies within globalised markets, and the potential impacts of climate change on these interdependencies, there is increasing value placed on the contribution of NEXUS framework planning to ensure sustainable futures. The interdependencies between water, energy and food within any individual economy, combined with the perturbances caused by climate change, creates a 
nexus; a latin term to describe 'that which is bound or tied together'. From this perspective, planning for water resources management must be made in concert with future energy use and innovation and with national food security. Unlike free market thinking, NEXUS framework theorists argue that these long term societal adaptations or transformations can only be optimised through state level planning, with the success or failure of one part of the nexus impacting significantly on another (Benson et al 2014).

Whilst it is possible to objectively detail the types of macro level planning needed to operationalise NEXUS approaches, there is a dearth of empirical data which details how citizens who both are impacted by these policies and who elect the politicians who shape and enact this policies interpret and understand these adaptive, transformative changes. There is a three stage challenge. Firstly to formulate national policy which will underpin sustainable futures within globalised economies. Secondly, to communicate the importance of these policies and the impact they will have on individual lifestyles. Thirdly to effectively communicate sustainable policies and strategies at a societal level we first need to understand how water users themselves comprehend the challenges that management practitioners face. Understanding this will enable a closer correspondence between policy intention and policy interpretation.

We have then a potential 'legitimacy gap' (Gearey and Jeffrey 2010) between asking people to radically alter how they currently use and value water whilst profit making privatised water companies are closely involved in the provision of that water supply. Policies which utilise the sustainability or climate change narrative may fall short due to the contested nature of privatised water delivery. Due to the expectations of service delivery associated with the private sector this may add to the challenge of attenuating everyday lifestyle choices. We need to know where water 'sits' within the lives of ordinary citizens. This next section of the paper details a piece of empirical fieldwork which aims to capture how citizens both interpret changes to their water environments and how this maps onto current and future water resources management practices.

\section{Methods}

This paper details empirical research conducted within three co-located villages, adjacent to a small river catchment, the River Adur, based in the South East of the UK. Projections over the next twenty five years indicate that this part of the country will experience conditions of increasing water stress. Drivers include the region having endemic low rainfall, growing population density and high land prices making mitigation strategies expensive. Through a series of interviews with a wide variety of water users we begin to uncover opinions, strategies, actions, knowledges and connectivities which reveal what is found at the watershed level. Using these fieldnotes we begin to build a picture to understand how macro level initiatives to support the sustainability of water resources are both understood by citizens and how they are incorporated into what Habermas (1984) drawing on Hussrl describes as the 'lifeworld' of the social. The research highlights the multiple ways that sustainability is understood and is contextualised by the lived experience at the watershed. The community stores shared with the research are intimately linked with the lifeworld and the lived experience of the narrator. This intimacy leads the research away from hard conclusions, but towards an 
appreciation for how the experiential is crucial for fixing sustainable practices at the micro level.

Adger's et al's work (2005) exploring adaptive capacity has highlighted the importance of place connectivity. Our individual and community psyche is attached to our surroundings, whether taskscape (Ingold 1993) or landscape, and our ability to effect or enact innovations, adaptations or wider transformations is influenced by these intimate connections between ourselves, our community and our environment. Scannell and Gifford's work (2012) on climate change messaging and community goes further to suggest that it is 'place attachment' combined with Meyers et al (2012) local messaging that improves the breadth and longevity of engagement with global warming issues. Understanding where water 'sits' within people's everyday lives will have direct relevance for how we manage water at a river catchment or 'micro' level, and for a wider macro perspective for planning around critical NEXUS infrastructures.

Contacts were made within the study area through generating contacts with community archive and heritage sites. These initial inroads into finding out about the life of the local communities' water resources then began to uncover contact points for those people and organisations who were involved in dialogues about water. In all, twenty eight one to one and small group interviews with respondents were undertaken across the three study sites covering a wide range of age, experiences, interests, expertise and knowledges.

\section{Results}

\section{Riverbank Story 1: 'Row Row Row Your Boat'}

In this first story of sustainable practices we have four storytellers. The 'riverbank' is in fact a small residential street, which is home to a year-round stream which runs alongside it, fed by natural springs. The above quote comes from a village resident who remembers taking her daughter to the lane to sail homemade paper boats on the 'little river' of her daughter's childhood.

The residential lane in question is based at the end of a long slow slope which leads to the South Downs National Park in West Sussex, a county within the South East of the United Kingdom. The South Downs are formed of gently undulating grassland, based on a porous chalk topography from which natural springs are a key feature. This particular section of the downland is partly managed by the South Downs National Park Authority, who are the local planning authority, and a large local landowner who privately owns the land. The lane in question has a number of small springs which converge on the lane and form a year-round small stream which varies in size according to the time of year and rainfall levels. It is therefore a consistent feature and one for which the lane is renowned. Residents moving here would be aware of it due to its year round prominence. One interviewee, who does not live in the lane, told me it was well used by local parents as a play area to float boats and let children splash in their wellington boots.

Local residents attribute three changes in circumstance which seem have altered the stream's benign status. Firstly, changing highways maintenance. There is a clear narrative that as local district and county councils, the meso level administrative authority structure, strip back resources due to financing constraints, they have changed the 
frequency and extent of work needed to maintain the grips, culverts, drains, cutaways and other man-made diversions which traditionally let the stream flow in a steady fashion along the surface of the lane to eventually join an underground sewer. Over time, as the maintenance frequency and scale decreased and local council teams were replaced with subcontractors unfamiliar with the idiosyncracies of the lane, residents argue there is a concordant perception that expertise is lost. As a result drains collapse and block, grips get filled and fail to redirect water to fallow ground alongside the lane, and leaves and other debris blocks the stream channel, causing it to billow out and spill across the road. The resulting pools of stagnant water rot the mortar of residential garden walls, scour the roadway itself and this debris is constantly washed against walls and cars as traffic passes along the lane. For residents the situation is so bad in the wetter winter months that they constantly have to wear wellington boots to gain entry and exit to their homes, and post and deliver drivers refuse to access the residential part of the lane while it is flooded.

The second change prevalent in the residents' dialogue is connected with land management practices higher up the lane. This is attributed by the residents to both the planning authority and the local landowner. The residents argue that drains managed by both parties are not being maintained leading to field water, rather than spring water, cascading down the lane. In return the landowners argue that their drains are maintained at great cost but that to divert the extra water, which they determine is the result of heavy rainfall events, requires support from the local councils due to the scales of costs involved. This then feeds into a separate discussion regarding planning for climate change and indicators of climate change.

A third narrative is that of satellite navigation. In their retelling of the lane's chronology, problems accelerated when this technology became widespread. Now GPS systems reroute overly large trucks and delivery vans down this small lane as they try to access the landowners' country estate and its onsite businesses and tenants at the top of the slope. The estate landowners say they clearly use a postcode which would signal to delivery drivers and visitors an alternative route, but it is the technology itself that directs drivers to use the lane. Meanwhile the parish council, the lowest tier of local authority, states that they have no monies to pay for highways signage to deter drivers from accessing the lane and suggest that the residents themselves fundraise to enable them to pay for their own signage. For local residents this is the final indignity, asked to fundraise for a problem not of their own making and which they feel no-one is assisting them to mitigate.

The residents' response has been to use social media to highlight their concerns, to petition the parish council to assist in highways maintenance and to collaboratively work together to research legal documents and other forms of official data to support their campaign. Their arguments are pivoted around living in harmony with the stream, and they have brought drainage engineers' reports and sustainable urban drainage management techniques into the debate to highlight affordable, environmentally sensitive ways to manage the natural passage of water in a small residential lane. For them, they want the other actors involved, the parish, district and council councils, the estate owner and the South Downs National Park Authority, to acknowledge their responsibility in managing the water on their land and make a fair contribution to paying for ongoing maintenance and drainage infrastructures. 
This community story reveals how what was historically a symbiotic relationship between residents and council, within which both undertook work which reflected local knowledges and the general upkeep of an area, has changed into a bureaucratic, officious and hamstrung dialogue. What is reflected is a complex interplay of clashing realities on the part of the lane's residents. The narrative they offer is a wish to live ergonomically and simply with a sympathetic relationship with a natural watercourse. Yet in order to make this possible what is required is financial investment and an entente approach to managing the needs and desires of the SDNPA and the landowner higher upstream. This mediation falls to the parish council, who are themselves elder volunteers with often little experience in managing technical data. The residents have then, in many ways, what could almost be regarded as outdated expectations of the competency of parish councils, who have had to take on more responsibility as local councils divest themselves of staff and commitments as they respond to financial pressure stemming from central government's austerity cut backs. There is then a tension between duties and expectations which feeds into the paradigm of sustainability. Our second community story goes further.

\section{Riverbank Story 2: 'If you get it right for the fish you get it right for everything else'}

In our second community story we explore the way in which sustainability can often develop from counter-intuitive sources. Within the study area there are several active voluntary groups each with their own orientation around environmentalism and sustainability. One group campaigns within their local neighbourhood to reduce energy use within domestic homes and is active in organising awareness raising events, holding open access talks and getting involved in educational interventions. Another leads a community orchard project to get people involved in growing their own fruit and socialising with others. The intent is clear and well understood with sustainability at its heart. A third group is involved in a range of conservation and wildlife protection actions, including clearing habitats for birdlife, opening scrubland areas to encourage nesting grounds and also re-naturalising rivers to support fish spawning. It is in this last area that a number of the interviews were orientated. These conservationists were very supportive of the research not least because it was an opportunity to highlight work which, by its very nature, needed to remain invisible. As they stated: 'if you get it right for the fish you get it right for everything else'.

There is then a close relationship between the conservationists who clear the smaller streams of debris and fundraise to buy and place large quantities of gravel; the anglers whose licences help support these activities and whose campaigns to improve water quality locally and nationally is impactful and the local rivers' and wildlife trust who provide advice and additional volunteers. Of great importance are the elder cohort of volunteers. This is not only because they are retired and have more time to get involved, but also because their memories of rivers feeds into a body of expertise which ensures that knowledge is passed on. All the villages have a high percentage of in-migration of residents, particularly retired residents, this knowledge is not directly attributable to the river itself or long standing place based expertise. Instead it is a mobile, hybrid set of 
knowledges which combine to provide generic understandings of riverine life and riparian ecosystems.

\section{Discussion}

These riverbank tales enable us to reflect on sustainable development narratives The responses were experiential, physical and communal in nature. What is revealed is the hybrid nature of the knowledges exchanged, developed and built upon. There is a tendency within some of the literature concerning lay or local knowledges and the environment to move towards idealising the lived experience. Within some of the work there is an emphasis on place-based knowledge, intra-generational knowledge and a linking of the self as a direct extension of the immediate environment (Whatmore 2009, Adger et al 2005). Whilst this is perfectly valid and useful within the context in which these pieces of work were undertaken, for sustainable management practises to thrive there has to be some kernel of application which can be translated across communities, across nations, across different development trajectories.

These two Riverbank Stories reveal the all encompassing importance of the immediate in the way we make sense of our world. The inchoate, abstracted idea of 'out there' makes the sustainability agenda feel remote and removed. Throughout the fieldwork the term 'sustainability' or even 'climate change' rarely appeared. The work that was being undertaken, the actions taken to improve or argue for the improvement of river water quality, utilised individual heuristics of what functioning watercourses should look like and in what form they should appear. The respondents therefore showed quite narrow horizons of how their local water resource issues fit into the bigger national or global picture. What links these three stories is the way in which it is the need to action something locally which galvanises responses - whether neighbours along a street, episodic village meetings in response to algae blooms and foul smelling water, or protecting streams to support recreational angling.

These stories suggest that what enables change is creating forum in which very immediate issues can be discussed, explored and enacted. Potential could lie then in communicating sustainability messages through making local issues connect to wider macro level agendas. This involves finding ways to support a deeper engagement between the stakeholders within these micro communities, which together combine, potentially, to not only enlighten and empower people within communities but to allow them to see the interconnectedness between events and processes. This is not to say people are unwilling or unable to do this by themselves, but rather that this ability requires a neutral space, experienced facilitators and time dedicated to make these linkages.

Within the context of NEXUS thinking and renewable freshwater resources the empirical fieldwork shows that there is a vernacular understanding of what it means to be sustainable in relation to sustainable water management practices - what seems to hamper enabling sustainability are the impediments of reduced resources within and above the community level. In the first story parish councils are run by elder volunteers with no experience and no access to additional finance whilst upstream riparians are trying to be sustainable within tight financial constraints. In the second narrative the 
pragmatic approach to river clearing and cleaning has been undertaken by volunteers whose horizon remains resolutely bound together with species sustainability - offering a glimpse of possible future ways of broadening this narrative to encompass sustainability more generally .

A broad perspective would argue that to enable sustainability you simply need to support and nurture the processes and practices already visible. This means financial support and other, more transformative changes.

\section{Conclusions}

Reviewing both stories we see evidence of attempts to support freshwater sustainability. In the flooded lane the residents want to live harmoniously with the water - but need support in order to do that. In the second story there is the recognition that when faced with pressing water issues community response will galvanise - although fleetingly. In the third, a thriving ecosystem is seen to be beneficial for all. And yet there is a limited horizon in all three.

These riverbank tales reveal in more nuanced detail the difficulties faced by policy makers, educationalists and environmental campaigners attempting to persuade citizens to embrace sustainable futures discussions. Most routes to assessing the success of public engagement with climate change data ask respondents about climate change directly. Through this piece of research, focusing on water resource issues, we have explored if local actors are able to make cognitive leaps to join up the strands of the sustainability narrative and make links across scientific disciplines. What we find is that the climate change 'story' has not filtered down. The term may be common - though we should be pertinent of the fact that over half the respondents made no direct allusions to it at all but is not clearly understood. There are differences in understanding likely scenarios in terms of temperature changes and seasonality, in global warming or cooling and no spontaneous connection with how this may affect, in this study at least, water resources. We can say that respondents' horizons are limited, contested and to a great extent disengaged when contextualised with sustainable futures.

To make sense of the overarching climate change narrative, those tasked with communicating climate change messages need to rewrite the script to show how these localised knowledges and experiences are central to making positive change happen. Agency needs to be re-appropriated by individual actors. This fieldwork sheds light on the micro level of everyday perspectives, opinions and practices which support sustainable water resources management. To support sustainable social practices and promote policies, technologies and lifestyle changes which all champion freshwater resource integrity there needs to be deeper engagement with community groups and businesses at the catchment level. Understanding the different lifeworld perspectives provides opportunities rather than barriers, and allows for targeted messages which accords with individual's own experiences. 


\section{References}

Adger, W. N., Arnell, N. W. \& Tompkins, E. L. (2005). Adapting to climate change: perspectives across scales. [in special issue: Adaptation to Climate Change: Perspectives Across Scales] Global Environmental Change Part A, 15, (2), 75-76.

Allan, J.A. (2003). IWRM/IWRAM: A new sanctioned discourse? Water Issues Study Group. London: University of London. Discussion Paper No. 50.

Benson, D., Gain, A.K. \& Rouillard, J.J. (2014). Water Governance in a Comparative Perspective: From IWRM to a 'Nexus' Approach? Water Alternatives. 8, (1), 756-773.

Biswas, A. (2008). Integrated Water Resources Management: Is It Working? International Journal of Water Resources Development. 24, (1), 5-22.

Brugnach, M., Dewulf, A., Pahl-Wostl, C. \& Taillieu, T. (2008). Toward a relational concept of uncertainty: about knowing too little, knowing too differently, and accepting not to know. Ecology and Society. 13(2): Art 30. [online] URL: http:// www.ecologyandsociety.org/vol13/iss 2/art30/.

Dovers, S.R. \& Handmer, J.W. (1992). Uncertainty, sustainability and change. Global Environmental Change. 2,(4), 262-276.

Gearey, M. \& Jeffrey, P.J. (2010). Using legitimacy dialogues to explore flooding issues in a UK catchment. Water and Environment. 24, 320-327.

Grahame, K. (2005). The wind in the willows. Penguin: London.

Habermas, J. (1984). The theory of communicative action: Volume 1. Beacon, Boston.

Hirsch, P. (2011). IWRM as a participatory governance framework for the Mekong River Basin? In J.Öjendal, S. Hansson, \& S. Hellberg (Eds.), Politics and Development in a Transboundary Watershed The Case of the Lower Mekong Basin. (pp155-170). Springer:Netherlands.

IPCC. (2012). Managing the Risks of Extreme Events and Disasters to Advance Climate Change Adaptation: A Special Report of Working Groups I and II of the Intergovernmental Panel on Climate Change. Cambridge, UK: Cambridge University Press, and New York, USA: Cambridge University Press.

Jeffrey, P.J. \& Gearey, M. (2006). Integrated water resources management: lost on the

road from ambition to realisation?. Water Science \& Technology. 53, (1), 1-8.

Poerksen, U. (1995). Plastic words. The tyranny of a modular language. University Park, PA: Penn State Press.

Scannell, L., \& Gifford, R. (2010). Defining place attachment: A tripartite organizing framework. Journal of Environmental Psychology. 30, 1-10.

Strang, V. (2004). The meaning of water.Berg press, Oxford.

Walker, W. E., P. Harremoës., J. Rotmans., J. P. van der Sluijs., M. B. A. van Asselt., P. Janssen., \& M. P. Krayer von Krauss. (2003). Defining uncertainty. A conceptual basis for uncertainty management in model based decision support. Integrated Assessment. 4, 5-17. 